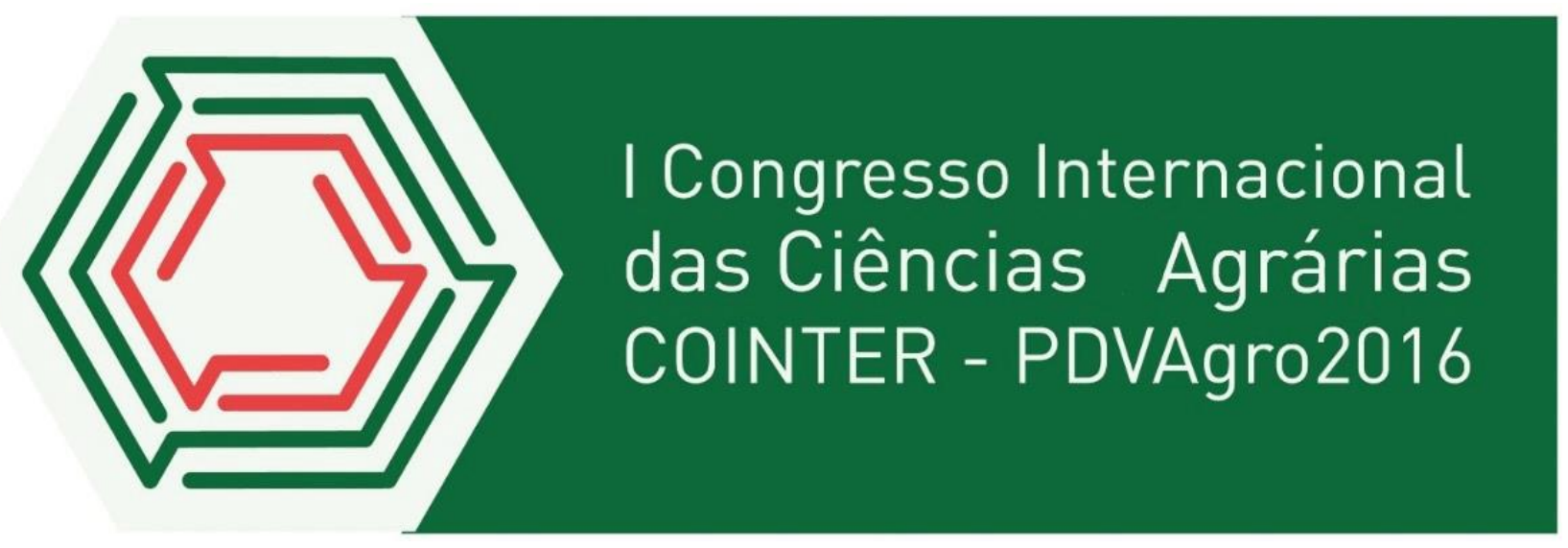

\title{
CLASSIFICAÇÃO SUCESSIONAL DAS ESPÉCIES PRESENTES NA CHUVA DE SEMENTES EM DOIS FRAGMENTOS DE FLORESTA TROPICAL ÚMIDA EM PERNAMBUCO
} Priscila Silva dos Santos ${ }^{1}$; Kleber Andrade da Silva ${ }^{2}$; Josiene Maria Falcão Fraga dos Santos ${ }^{3}$;
Elcida de Lima Araújo ${ }^{4 ;}$ Elba Maria Nogueira Ferraz

\section{Introdução}

A classificação das espécies em grupos funcionais representa uma ferramenta de fundamental importância para o entendimento da sucessão ecológica em florestas tropicais (PAULA et al., 2004; CHAZDON et al., 2010). A utilização de grupos funcionais auxilia a compreender a resposta da vegetação e o histórico de variabilidade ambiental, e ainda possibilita prever como a vegetação responderá as alterações ambientais e antrópicas (REICH et al., 2003; DÍAZ; CABIDO, 1997).

No Brasil, uma das classificações em grupos sucessionais mais usada é a proposta por Gandolfi et al. (1995). Com a finalidade de melhor discutir os aspectos associados à sucessão secundária os autores sugeriram quatro níveis de categorias sucessionais para as espécies: pioneira, secundárias iniciais, secundárias tardias e sem caracterização.

Os remanescentes de florestas úmidas localizados em áreas rurais e urbanas evidenciam que apesar das espécies apresentarem diferentes percentuais quanto à categoria sucessional, áreas rurais e urbanas mostram uma elevada proporção de espécies pioneiras e secundárias iniciais (DUCAN; CHAPMAN, 1999; FREITAS et al., 2013; OLIVEIRA et al., 2011). Com base na evidência de que a classificação sucessional das espécies via chuva de sementes pode auxiliar na identificação do

\footnotetext{
${ }^{1}$ Programa de Pós-graduação em Botânica - PPGB, Universidade Federal Rural de Pernambuco - UFRPE, biopri13@ hotmail.com

${ }^{2}$ Centro Acadêmico de Vitória - Universidade Federal de Pernambuco, kleberandradedasilva@ hotmail.com ${ }^{3}$ Pós doutoranda do Programa Nacional de Pós-Doutorado - CAPES, UFRPE, enefalcaoo@hotmail.com

${ }^{4}$ PPGB, UFRPE, elcida@db.ufrpe.br

${ }^{5}$ PPGB, UFRPE, elbanogueira@ superig.com.br
} 
grau de conservação de uma área, este estudo propôs testar a hipótese de que as espécies de início de sucessão (pioneiras e secundárias iniciais) serão predominantes independentemente dos fragmentos. Para isto, este estudo tem como objetivo caracterizar e comparar a categoria sucessional da chuva de sementes em fragmentos urbano e rural de floresta Atlântica.

\section{Fundamentação Teórica}

A chuva de sementes é definida como um processo ecológico caracterizado pela fonte de propágulos que chegam ao solo através de diferentes mecanismos de dispersão (CAMPOS et al., 2009). Esse processo é fundamental na recuperação de áreas degradas e na regeneração natural por possibilitar a disseminação e perpetuação das espécies vegetais. No entanto, o grupo de espécies que irão ter sucesso na germinação numa área em regeneração dependerá do estágio sucessional da floresta em questão.

Durante o processo sucessional as espécies de início de sucessão (pioneiras) investem em crescimento rápido (altura) e formam caules finos e susceptíveis a ruptura, o que pode prejudicar a sua chegada ao dossel da floresta. Em contrapartida, as espécies tolerantes à sombra apresentam crescimento lento, geralmente formam copas mais desenvolvidas, capturam luz com maior eficácia e aumentam o diâmetro do caule conforme sua aproximação com o dossel (MOTGOMERY; CHADZON, 2001).

Além disso, no decorrer da sucessão, a comunidade vegetal tende a sofrer alterações na sua composição florística, devido à entrada de espécies pertencentes aos primeiros estágios de sucessão, encontradas no estrato regenerativo, com posterior substituição das espécies de estágios mais avançados, encontradas no estrato arbóreo (SALLES; SCHIAVINI, 2007).

\section{Metodologia}

Caracterização da área de estudo

O estudo foi desenvolvido na Região Metropolitana do Recife, Nordeste do Brasil, em dois remanescentes de floresta Atlântica, denominados Parque Estadual de Dois Irmãos (PEDI), localizado na cidade de Recife, e Refúgio de Vida Silvestre Matas do Sistema Gurjaú (RVS de 
Gurjaú) no Cabo de Santo Agostinho. Neste estudo, o PEDI e o RVS de Gurjaú foram denominados de fragmento urbano e rural, respectivamente.

Amostragem da chuva de sementes

Em cada fragmento (urbano e rural) foram instalados 36 coletores, totalizando 72. Os coletores foram distribuídos em três transectos de 300 metros, interespaçados a aproximadamente 100 metros de distância. Em cada transecto, foram instalados 12 coletores equidistantes a $25 \mathrm{~m}$. Os coletores apresentam área de $0,25 \mathrm{~m}^{2}$ e foram instalados a $30 \mathrm{~cm}$ acima do solo (KNORR; GOTTSBERGER, 2012; SILVA et al., 2014; SANTOS, 2014). Estes foram confeccionados de forma quadrada, com malha de nylon de $1 \mathrm{~mm}$, com profundidade de $\approx 20 \mathrm{~cm}$, e foram fixados com auxílio de fios de nylon em troncos de árvores e identificados com placa numerada. A coleta do material foi feita mensalmente de fevereiro/2015 a janeiro/2016. No laboratório as sementes foram separadas manualmente de outros materiais e classificadas quanto à categoria sucessional em pioneiras, secundárias iniciais e secundárias tardias (GANDOLFI et al., 1995). A categoria sucessional correspondente a cada espécie foi avaliada por consultas a literatura local (MARANGON et al., 2010; OLIVEIRA et al., 2011; SILVA; RODAL, 2009).

Análise dos dados

O teste Qui-quadrado com correção de Yates foi utilizado para verificar se a categoria sucessional das espécies presentes na chuva de sementes diferem entre os fragmentos.

\section{Resultados e Discussões}

A análise do teste Qui-quadrado mostrou que a categoria sucessional das espécies presentes na chuva de sementes não diferiram significativamente entre os fragmentos urbano e rural (Tabela 1). Apesar de não serem significativas às diferenças, constatou-se que as espécies de início de sucessão (pioneiras e secundárias inicais) foram predomiantes na proporção total de espécies registradas em ambos os fragmentos, com 59\% no urbano e 52\% no rural (Tabela 1).

Tabela 1. Atributos funcionais das espécies presentes na chuva de sementes nos fragmentos urbano e rural de floresta Atlântica em Pernambuco. Letras diferentes entre colunas indicam diferenças estatísticas pelo teste do QuiQuadrado. 


\section{Categoria Sucessional}

Pioneira

Secundária Inicial

Secundária Tardia
$10(22 \%) \mathrm{a}$

$15(37 \%) \mathrm{a}$

$13(28 \%)$ a
$11(24 \%) \mathrm{a}$

$13(28 \%) \mathrm{a}$

$9(19 \%) \mathrm{a}$

A hipótese de que as espécies de início de sucessão (pioneiras e secundárias iniciais) seriam dominantes na chuva de sementes de ambos os fragmentos foi confirmada. O elevado percentual de espécies de início de sucessão, 59\% no fragmento urbano e 52\% no rural pode ser um indicativo de que as florestas não atingiram a maturidade, ou ainda, pode-se deduzir que essa maturidade foi atingida, porém a presença de alguma perturbação natural ou antrópica, como por exemplo, abertura de clareiras, tenha levado ao aparecimento de um maior número dessas espécies. Pode-se inferir que ambas as vegetações estão condicionadas a passar por sucessivas modificações na estrutura e composição, o que implicará a substituição desses grupos de início de sucessão por grupos de espécies tardias, conduzindo ambas as áreas a fragmentos florestais maduros. Apesar dessas modificações serem reconhecidas, Burley et al. (2008) afirmam que as florestas urbanas possivelmente apresentaram diferentes trajetórias sucessionais quando comparadas com florestas rurais, devido à presença de "fatores de estresse" atrelados às cidades. No entanto, podemos sugerir que ambas as florestas passam pelas mesmas trajetórias, porém o tempo em que cada categoria sucessional leva até atingir a próxima possivelmente pode variar em função da frequência em que ocorre determinadas pressões (antrópicas ou naturais).

\section{Conclusões}

Ao analisar a classificação sucessional das espécies por grupo ecológico, pode-se notar que os fragmentos urbano e rural possuem em sua maioria espécies pioneiras e secundárias iniciais, denominando-os em fragmentos jovens em estágio inicial de sucessão. 


\section{Referências}

BURLEY, S.; ROBINSON, S. L.; LUNDHOLM, J. T. Post-hurricane vegetation recovery in an urban Forest. Landscape and Urban Planning, v.85, n. 2, p. 111-122, 2008.

CAMPOS, E. P.; VIEIRA, M. F.; SILVA, A. F.; MARTINS, S. V.; CARMO, F. M. S.; MOURA, V. M.; RIBEIRO, A. S. S. Chuva de sementes em Floresta Estacional Semidecidual em Viçosa, MG, Brasil. Acta Botanica Brasilica, v. 23, n. 2, p. 451-458, 2009.

CHAZDON, R. L.; FINEGAN, B.; CAPERS, R. S.; SALGADO-NEGRET, B.; CASANOVES, F.; BOUKILI, V.; NORDEN, N. Composition and Dynamics of Functional Groups of Trees During Tropical Forest Succession in Northeastern Costa Rica. Biotropica, v. 42, n. 1, p. 31-40, 2010.

DÍAZ, S.; CABIDO, M. Plant functional types and ecosystem function in relation to global change. Journal of Vegetation Science, v. 8, n. 4, p. 463-474, 1997.

DUNCAN, R. S.; CHAPMAN, C. A. Seed dispersal and potential forest succession in abandoned agriculture in tropical Africa. Ecological Applications, v. 9, n. 3, p. 998-1008, 1999.

FREITAS, C. G.; DAMBROS, C.; CAMARGO, J. L. C. Changes in seed rain across Atlantic Forest fragments in Northeast Brazil. Acta Oecologica, v. 53, p. 49-55, 2013.

GANDOLFI, S.; LEITÃO FILH0, H. F.; BEZERRA, C. L. Levantamento florístico e caráter sucessional das espécies arbustivo-arbóreas de uma floresta mesófila semidecídua no município de Guarulhos, SP. Revista Brasileira de Biologia, v. 55, n.4, p. 753-767, 1995.

MARANGON, G. P.; CRUZ, A. F.; BARBOSA, W. B.; LOUREIRO, G. H.; HOLANDA, A. C. Dispersão de sementes de uma comunidade arbórea em um remanescente de mata Atlântica, município de Bonito, PE. Revista Verde, v. 5, n. 5, p. 80-87, 2010.

MOTGOMERY, R. A.; CHADZON, R. L. Forest structure, canopy architecture, and light transmittance in tropical wet forest. Ecology, v. 82, n. 10, 2707-2718, 2001.

OLIVEIRA, L. S. B.; MARAGON, L. C.; FELICIANO, A. L. P.; LIMA, A. S.; CARDOSO, M. O.; SILVA, V. F. Florística, classificação sucessional e síndromes de dispersão em um remanescente de Floresta Atlântica, Moreno-PE. Revista Brasileira de Ciências Agrárias, v. 6, n. 3, p. 502-507, 2011.

REICH, P. B.; WRIGHT, I. J.; CAVENDER-BARES, J.; CRAINE, J. M.; OLEKSYN, J.; WESTOBY, M.; WALTERS, M. B. The evolution of plant functional variation: traits, spectra, and strategies. International Journal of Plant Sciences, v. 164, n. 3, p. 143-164, 2003.

PAULA, A.; SILVA, A. F.; JÚNIOR, P.M.; SANTOS, F. A. M.; SOUZA, A. L. Sucessão ecológica da vegetação arbórea em uma Floresta Estacional Semidecidual, Viçosa, MG, Brasil. Acta Botanica Brasilica, v. 18, n. 3, p. 407-423, 2004.

KNORR, U. C.; GOTTSBERGER, G. Differences in seed rain composition in small and large in the northeast Brazilian Atlantic Forest. Plant Biology, v.14, p. 811-819, 2012. 
SALLES, J. C.; SCHIAVINI, I. Estrutura e composição do estrato de regeneração em um fragmento florestal urbano: implicações para a dinâmica e a conservação da comunidade arbórea. Acta Botanica Brasilica, v. 21, n. 1, p. 223-233, 2007.

SANTOS, P. S. Avaliação da chuva de sementes em um fragmento urbano de floresta atlântica em Pernambuco, Brasil. 2014. 80f. Dissertação (Mestrado em Botânica) - Universidade Federal Rural de Pernambuco, Recife, 2014.

SILVA, C. R. B.; SILVA, F. F.; FERREIRA, E. B.; POLO, M. Chuva de sementes em fragmento de floresta atlântica semidecídua. Revista da Universidade Vale do Rio Verde, v. 12, n. 1, p. 621$635,2014$.

SILVA, M. C. N. A.; RODAL, M. J. N. Padrões das síndromes de dispersão de plantas em áreas com diferentes graus de pluviosidade, PE, Brasil. Acta Botanica. Brasilica, v. 23, n. 4, p. 1040 - 